\title{
Intake of Beer, Wine and Spirits and Risk of Heavy Drinking and Alcoholic Cirrhosis
}

\author{
MORTEN GRØNBÆK ${ }^{1}$, MAJKEN K JENSEN ${ }^{1}$, DITTE JOHANSEN ${ }^{1}$, THORKILD I A \\ SØRENSEN ${ }^{1}$ and ULRIK BECKER ${ }^{2}$
}

\begin{abstract}
${ }^{1}$ Centre for Alcohol Research, National Institute of Public Health, Copenhagen, Denmark. ${ }^{2}$ Alcohol Unit and Gastrounit, Division of Medical, Gastroenterology, Copenhagen University Hospital, Hvidovre, Denmark. Copenhagen Centre for Prospective Population Studies, Danish Epidemiology Science at the Institute of Preventive Medicine, Copenhagen University Hospital, Copenhagen, Denmark.
\end{abstract}

\begin{abstract}
Studies have suggested that wine drinkers are at lower risk of death than beer or spirit drinkers. The aim of this study is to examine whether the risk of becoming a heavy drinker or developing alcoholic cirrhosis differs among individuals who prefer different types of alcoholic beverages.

In a longitudinal setting we found that both the risk of becoming a heavy or excessive drinker (above 14 and 21 drinks per week for women and above 21 and 35 drinks per week for men) and the risk of developing alcoholic cirrhosis depended on the individuals preference of wine, beer or spirits. We conclude that moderate wine drinkers appear to be at lower risk of becoming heavy and excessive drinkers and that this may add to the explanation of the reported beverage-specific differences in morbidity and mortality.
\end{abstract}

Key words: Alcohol, alcoholic cirrhosis, beer, beverage preference, excessive drinking, heavy drinking, spirit, wine.

\section{INTRODUCTION}

A light to moderate intake of alcohol has been suggested to reduce morbidity and mortality (1-4). Several recent studies have shown that wine drinkers compared to beer and spirits drinkers are at lower risk of death from all causes (5-8). This may be due to the fact that beer contains possibly carcinogenic nitrosamines (9), whereas wine may have additional cardioprotective and anticarcinogenic properties different from those of ethanol (7, 10-12). The differences in morbidity and mortality may to some extent be explained by confounding factors such as diet (13), subjective health (14), binge versus steady drinking (15), or other correlates of preferred type of alcoholic beverage. Another explanation for the differences may be that beer and spirit drinkers could be more inclined to increase their level of alcohol consumption. Apart from that, it was also the aim of this investigation to study whether there were different effects of the different types of alcoholic beverages on the risk of alcoholic cirrhosis.

\section{SUBJECTS AND METHODS}

\section{Population}

These analyses were based on data from two comprehensive Danish population studies compiled in the Copenhagen Centre for Prospective Population Studies: the Copenhagen City Heart Study and the Glostrup Population Studies. Baseline characteristics are shown in Table I. Detailed descriptions of the studies have been published previously (16-18). 
TABLE I

Odds ratios and $95 \%$ confidence intervals for becoming a heavy and an excessive drinker* according to beverage preference.

\begin{tabular}{|c|c|c|c|c|}
\hline \multicolumn{5}{|c|}{ WOMEN } \\
\hline & \multicolumn{2}{|c|}{$\begin{array}{c}\text { Heavy drinking } \\
(>14 \text { drinks per week) }\end{array}$} & \multicolumn{2}{|c|}{$\begin{array}{l}\text { Excessive drinking } \\
(>21 \text { drinks per week) }\end{array}$} \\
\hline & Crude & Adjusted $\dagger$ & Crude & Adjusted $\dagger$ \\
\hline Wine & 1.0 & 1.0 & 1.0 & 1.0 \\
\hline Beer & $1.25(0.95-1.63)$ & $1.14(0.87-1.50)$ & $1.70(1.08-2.77)$ & $1.50(0.93-2.43)$ \\
\hline Spirits & $0.96(0.65-1.42)$ & $0.85(0.58-1.27)$ & $1.84(1.00-3.38)$ & $1.51(0.81-2.82)$ \\
\hline Mixed & $0.91(0.70-1.18)$ & $0.83(0.64-1.09)$ & $1.02(0.63-1.68)$ & $0.91(0.55-1.50)$ \\
\hline
\end{tabular}

MEN

\begin{tabular}{|c|c|c|c|c|}
\hline & \multicolumn{2}{|c|}{$\begin{array}{c}\text { Heavy drinking } \\
\text { (>21 drinks per week) }\end{array}$} & \multicolumn{2}{|c|}{$\begin{array}{l}\text { Excessive drinking } \\
(>35 \text { drinks per week) }\end{array}$} \\
\hline & Crude & Adjusted $\dagger$ & Crude & Adjusted $\dagger$ \\
\hline Wine & 1.0 & 1.0 & 1.0 & 1.0 \\
\hline Beer & $1.46(1.09-1.95)$ & $1.16(0.84-1.58)$ & $2.37(1.14-4.95)$ & $1.81(0.85-3.82)$ \\
\hline Spirits & $1.01(0.68-1.77)$ & $1.09(0.66-1.81)$ & $0.96(0.25-3.69)$ & $0.85(0.22-3.32)$ \\
\hline Mixed & $1.03(0.75-1.42)$ & $0.87(0.62-1.23)$ & $1.54(0.69-3.41)$ & $1.26(0.56-2.84)$ \\
\hline
\end{tabular}

* "Heavy drinking" and "excessive drinking" are separate, dichotomous comparisons, including all study subjects.

$\dagger$ Adjusted for age, study of origin, smoking, educational level and total alcohol consumptio

\section{Questionnaire and examination}

Information on participants at both examinations included a health examination and a self-administered questionnaire concerning various lifestyle and healthrelated issues. The staff checked the responses to the questionnaires during the examination with regard to potential nonresponse or inconsistent responses. Participants were asked: "How many drinks of beer do you normally consume within a week?" The same was asked for wine and spirits. We assumed that the alcohol content per drink was roughly the same for the three types of drinks. A beverage preference was defined as the type of alcohol whose intake exceeded $50 \%$ of the total alcohol intake. Participants who did not have a preferred alcoholic beverage were defined as mixed drinkers.

\section{Definition of covariates}

Age was divided into quartiles (less than or equal to 44 years, 45-52 years, 53-60 years and 60 years or more). Subjects reported if they were never-smokers, former smokers, or current smokers. Current smokers were grouped as 1-14 grams of tobacco per day, 15-24 grams per day, or more than 24 grams per day (one cigarette was equivalent to $1 \mathrm{~g}$, a cheroot to $3 \mathrm{~g}$ and a cigar to $5 \mathrm{~g}$ of tobacco). Participants reported their level of education as less than or equal to 7 years of school, 8-11 years, or 12 or more years of 
school education. Subjects were asked if they were physically active during leisure time. Categories were sedentary, less than 4 hours per week, or more than or equal to 4 hours per week. Height and weight in light clothes without shoes were measured, and body mass index was calculated as weight $(\mathrm{kg})$ divided by squared height $\left(\mathrm{m}^{2}\right)$. This was included in the analysis as a continuous measure. Subjects reported whether they lived with a partner or not (grouping married and unmarried couples). Chronic diseases among the participants were assessed by use of the Danish National Hospital Admission Register according to diagnoses based on the WHO International Classification of Diseases, Eighth Revision (ICD-8 codes; 40-46, 79, 83, 93-95, 140209, 240-289, 340-358, 393-458, 490-493, 530-537, 560-569, 571-573, 577, 580-584, 710-739). A single covariate was used to designate those persons with any of the eligible chronic diseases.

\section{Outcome}

The outcome measures were heavy drinking, excessive drinking and alcoholic cirrhosis. Women were considered heavy drinkers at the second examination if they had a total weekly intake above 14, and men, if they had above 21 drinks per week. Excessive drinking was defined as more than 21 drinks per week for women and 35 drinks per week for men. Alcoholic cirrhosis was death or discharge with alcoholic cirrhosis defined according to the International Classification of Diseases (ICD-8) (ICD-8 code 571.09).

\section{RESULTS}

\section{Heavy and excessive drinking}

Using wine drinkers (the largest category) as the reference group, women who preferred beer had crude odds ratios of 1.25 (95 \% CI: 0.95-1.63) and 1.73 (95\% CI: 1.08-2.77) for heavy and excessive drinking. For men the odds ratios were 1.46 (1.09-1.95) and 2.37 (1.14-4.95) (Table I). Adjustment for total alcohol consumption weakened the association, and the fully adjusted analysis shows a modest tendency of men and women who prefer beer to become excessive drinkers. Stratified analysis showed that especially younger men drinking beer were at high risk of developing a heavy drinking pattern (Table II). Compared to wine drinkers as referent, the adjusted odds ratios among men who preferred beer were 1.16 (95\% CI: 0.841.58) for becoming a heavy drinker and 1.81 (95 \% CI: 0.85-3.82) for becoming an excessive drinker. Women who preferred beer had adjusted odds ratios of 1.14 (95\% CI: 0.87-1.50) and 1.50 (95 \% CI: 0.932.43) for heavy and excessive drinking, respectively. Also, women who preferred spirits had increased risks of excessive drinking as compared to wine-drinking women (odds ratio: 1.51, $96 \% \mathrm{CI}$ : 0.812.82). As a sensitivity analysis, other categories of alcohol consumption were applied. These analyses were all adjusted for age, study of origin, smoking and total alcohol consumption.

\section{Alcoholic cirrhosis}

A total of 292 individuals (80 women and 212 men) developed alcoholic cirrhosis during the observation period. When analyzing the separate effects of wine intake (drinks per week) adjusting for beer and spirits intake as well as adjusting for the other covariates, we found a relative risk for developing cirrhosis of 0.5 (95\% confidence limits 0.4-0.7) in the group drinking 1 to 7 drinks of wine per week and a relative risk of 0.6 (95\% confidence limits $0.3-1.0)$ and 2.5 (95\% confidence limits 1.1-5.7) respectively for the two groups drinking 8 to 21 drinks and more than 21 drinks of wine per week. The group drinking less than one drink of wine per week was used as reference (relative risk set at 1.0). The results of the final model including total alcohol intake (drinks per week) and wine percent are shown in Figure 1. An increase in risk of cirrhosis with increasing total alcohol intake was observed in all categories of wine percent. However, the risk of alcoholic cirrhosis was lower for wine drinkers compared to those 
TABLE II

Age-related odds ratios for becoming an excessive drinker according to beverage preference

\begin{tabular}{lcc}
\hline Beverage Preference & $\begin{array}{c}\text { YOUNGER MEN } \\
(\mathrm{N}=2,704)\end{array}$ & $\begin{array}{c}\text { OLDER MEN } \\
(\mathrm{N}=2,299)\end{array}$ \\
\hline Wine & 1.00 & 1.00 \\
Beer & $3.71(1.13-12.14)$ & $0.75(0.27-2.05)$ \\
Spirits & $2.08(0.21-21.21)$ & $0.38(0.07-2.04)$ \\
Mixed & $2.20(0.62-7.80)$ & $0.67(0.23-1.98)$ \\
\hline & YOUNGER WOMEN & $(\mathrm{N}=2,931)$ \\
Wine & 1.00 & OLDER WOMEN \\
Beer & $1.54(0.82-2.88)$ & 1.00 \\
Spirits & $1.10(0.36-3.33)$ & $1.53(0.72-3.25)$ \\
Mixed & $1.51(0.84-2.72)$ & $1.51(0.69-3.32)$ \\
\hline
\end{tabular}

Note: Estimates are controlled for study of origin, educational level, smoking and total alcohol intake. Median age (52 years) used as cutpoint

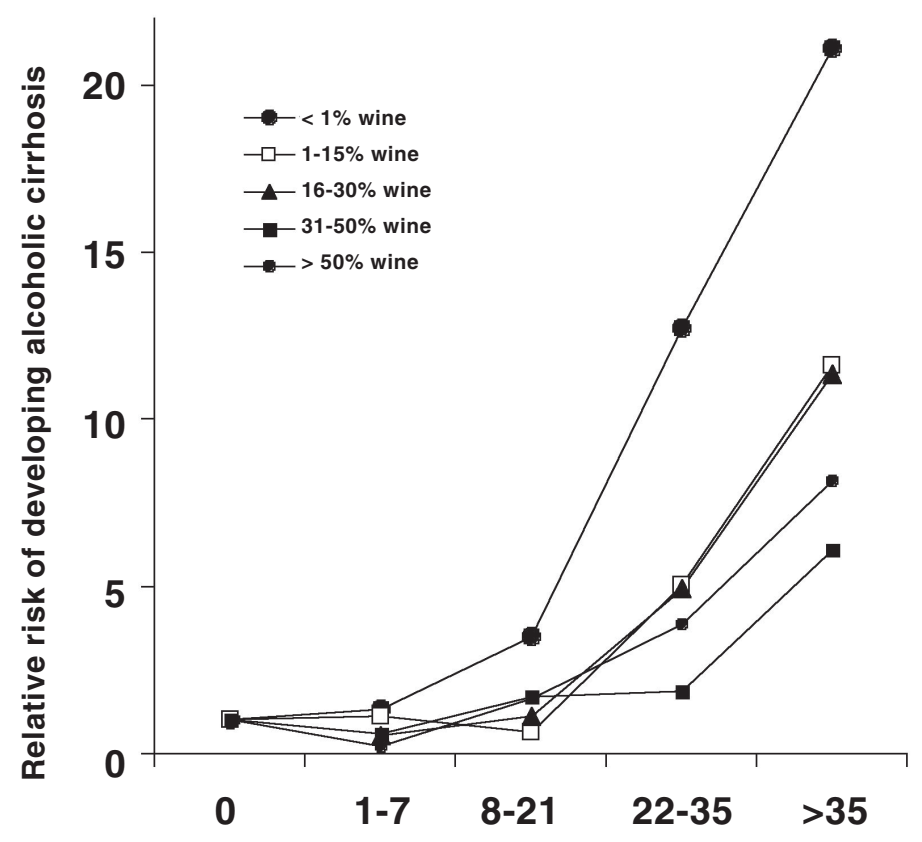

Total alcohol intake; drinks/week

Figure 1. Relative risks for developing alcoholic cirrhosis. Relative risks were adjusted for sex, age, smoking habits, BMI, educational level, and total alcohol intake. Individuals drinking $<1 \%$ wine of total alcohol intake in both genders combined were used as reference group (relative risk $=1.00$ ). Vertical bars are estimated $95 \%$ confidence limits. 
drinking no or little wine - even for heavy drinkers (total alcohol intake more than 35 drinks per week). For heavy drinkers who drank more than $50 \%$ of their alcohol intake as wine, the relative risk was 8.2 (95\% confidence limits 1.8 - 20.8) for developing cirrhosis compared to individuals drinking less than 1 drink per week (reference group; relative risk set at 1.0). In contrast, heavy drinkers who drank no wine had a relative risk for developing alcoholic cirrhosis of 21.1 (95\% confidence limits $12.4-36.1$ ).

\section{CONCLUSION}

The present study suggests that a person who prefers beer is more likely to become a heavy or an excessive drinker than a person who prefers wine. Among men, moderate drinkers who included wine in their weekly alcohol intake had significantly lower risks of becoming heavy or excessive drinkers as compared to those who did not drink any wine. Women who included beer in their alcohol intake showed increased risk of heavy and excessive drinking compared to non-beer drinking women. Further we found that the risk of developing cirrhosis in wine drinkers (more than $30 \%$ wine of total alcohol intake) was less than $50 \%$ of the risk in non-wine drinkers for any given level of total alcohol intake, while beer and spirits drinking did not modify the relation between total alcohol intake and risk of developing cirrhosis.

Other studies have reported relations between beer drinking and high-risk behaviors such as frequent heavy drinking and other alcohol-related problems, while wine drinking seems to be considered 'the beverage of moderation' (19-21). However, these studies were all cross-sectional and therefore inadequate for causal inferences. Our study was based on a large random sample of the population which was followed prospectively, thus reducing selection and recall bias.

Free radical formation after alcohol intake and a reduced level of antioxidants have been implicated in the pathogenesis of alcoholic liver disease (22-23). Nonalcoholic constituents of wine have antioxidant properties (24-25) and intake of red wine has been demonstrated to increase antioxidant activity in serum. Quercetin, a flavonoid, has been demonstrated to reduce oxidative damage to the liver in rats and resveratrol, as well as quercetin, can inhibit activation of rat hepatic stellate cells (2627). However, antioxidants are also abundant in diets with high contents of vegetables and fruits (28-29), and a causal relation between ingestion of these substances and a reduced risk of cirrhosis remains to be demonstrated.

The observed effect of wine drinking may merely reflect a lower risk of later excessive drinking or a lower risk of being exposed to the unknown additional risk factors that initiate liver damage in subjects conditioned by heavy drinking. The association between wine intake and other life style factors including current alcohol intake should also be studied in detail. The public health implications of these results remain to be determined as a causal relationship between wine drinking and beneficial health effects have not yet been established.

In conclusion, the finding that moderate wine drinkers appear to be at lower risk of becoming heavy and excessive drinkers as well as developing alcoholic cirrhosis may add to the explanation of the reported beverage-specific differences in morbidity and mortality.

These results have previously been reported in:

JENSEN MK, ANDERSEN AT, SØRENSEN TI, BECKER U, THORSEN T, GRØNBÆK M. Alcoholic beverage preference and risk of becoming a heavy drinker. Epidemiology 2002; 13(2):127-32, and

BECKER U, GRONBÆK M, JOHANSEN D, SØRENSEN TI. Lower risk for alcohol-induced cirrhosis in wine drinkers. Hepatology. 2002 Apr; 35(4):868-75. 


\section{REFERENCES}

1. MACLURE M (1993) Demonstration of deductive meta-analysis: Ethanol intake and risk of myocardial infarction. Epidemiologic Reviews 15:328-351

2. SHAPER AG (1990) Alcohol and mortality: a review of prospective studies. Br J Addict 85:837-847

3. KLATSKY AL, ARMSTRONG MA, FRIEDMAN GD (1992) Alcohol and mortality. Ann Intern Med 117:646-654

4. RIMM EB, KLATSKY A, GROBBEE D, and STAMPFER MJ (1996) Review of moderate alcohol consumption and reduced risk of coronary heart disease: is the effect due to beer, wine, or spirits. $\mathrm{Br}$ Med J 312:731-736

5. KLATSKY AL, ARMSTRONG MA (1993) Alcoholic beverage choice and risk of coronary artery disease mortality: do red wine drinkers fare best? Am J Cardiol 71:467-469

6. WANNAMETHEE SG, SHAPER AG (1999) Type of alcoholic drink and risk of major coronary heart disease events and all-cause mortality. Am J Public Health 89:685-690

7. GRØNBÆK M, BECKER U, JOHANSEN D GOTTSCHAU A, SCHNOHR P, HEIN HO, JENSEN G, SØRENSEN TIA (2000) Type of alcohol consumed and mortality from all causes, coronary heart disease, and cancer. Ann Intern Med 133:411-419

8. RENAUD S, GUEGUEN R, CONARD P (2004) Alcohol and Mortality from All Causes. Biol Res 37: 183-187

9. BERGER A (1998) Science commentary: Why wine might be less harmful than beer and spirits. BMJ 317:844

10. FRANKEL EN, KANNER J, GERMAN JB, PARKS E, KINSELLA JE (1993) Inhibition of oxidation of human low-density lipoprotein by phenolic substances in red wine. Lancet 341:454-457

11. SHIMADA $K$, WATANABE $H$, HOSODA $K$, TAKEUCHI K, YOSHIKAWA J (1999) Effect of red wine on coronary flow-velocity reserve. Lancet 354:1002

12. PRESCOTT E, GRØNBÆK M, BECKER U, SØRENSEN TIA (1999) Alcohol intake and the risk of lung cancer: Influence of type of alcoholic beverage. Am J Epidemiol 149:463-470

13. TJONNELAND A, GRØNBÆK M, STRIPP C, OVERVAD K (1999) Wine intake and diet in a random sample of 48763 Danish men and women. Am J Clin Nutr 69:49-54

14. POIKOLAINEN K, VARTIAINEN E, KORHONEN HJ (1996) Alcohol intake and subjective health. Am J Epidemiol 144:346-350

15. McELDUFF P, DOBSON AJ (1997) How much alcohol and how often? Population based case-control study of alcohol consumption and risk of a major coronary event. Br Med J 314:1159-1164
16. APPLEYARD M, HANSEN AT, SCHNOHR P, JENSEN G, NYBOE J (1989) The Copenhagen City Heart Study. A book of tables with data from the first examination (1976-78) and a five year follow-up (1981-83). Scand J Soc Med (suppl 41) 170:1-160

17. HAGERUP L, ERIKSEN M, SCHROLL M, HOLLNAGEL H, AGNER E, LARSEN S (1981) The Glostrup population studies. Collection of epidemiologic tables. Reference values for use in cardiovascular population studies. Scand J Soc Med (suppl) 20:1-112

18. SCHROLL M (1982) A ten-year prospective study, 1964-1974, of cardiovascular risk factors in men and women from the Glostrup population born in 1914. Dan Med Bull 29:213-252

19. SMART RG, WALSH G (1999) Heavy drinking and problems among wine drinkers. J Stud Alcohol 60:467471

20. SMART RG, WALSH GW (1995) Do some types of alcoholic beverages lead to more problems for adolescents? J Stud Alcohol 56:35-38

21. KLASKY AL, ARMSTRONG MA, KIPP H (1990) Correlates of alcoholic beverage preference: traits of persons who choose wine, liquor or beer. Br J Addict 85:1279-1289

22. REINKE LA, MOORE DR, McCAY PB (1997) Free radical formation in livers of rats treated acutely and chronically with alcohol. Alcohol Clin Exp Res. 21:642-646

23. NORDMANN R (1994) Alcohol and antioxidant systems. Alcohol Alcohol 29: 513-522

24. FRANKEL EN, KANNER J, GERMAN JB, PARKS E, KINSELLA JE (1993) Inhibition of oxidation of human low-density lipoprotein by phenolic substances in red wine. Lancet 341: 454-457

25. KAWADA N, SEKI S, INOUE M, KUROKI T (1998) Effect of antioxidants, Resveratrol, Quercetin, and NAcetylcysteine, on the functions of cultured rat hepatic stellate cells and Kupffer cells. Hepatology 27: 12651274

26. FUHRMAN B, LAVY A, AVIRAM M (1995) Consumption of red wine with meals reduces the susceptibility of human plasma and low-density lipoprotein to lipid peroxidation. Am J Clin Nutr 61: 549-554

27. TICCA M, SERAFINI M (1997) Wine, health and dietary modulation of oxidative stress: an up-date. Alcologia 9: 185-189

28. PERES W, TUÑON MJ, COLLADO PS, HERRMANN S, MARRONI N, GONZÁLEZ-GALLEGO J (2000) The flavonoid quercetin ameliorates liver damage in rats with biliary obstruction. J Hepatol 33: 742-750

29. HERTOG MGL, FESKENS EJM, HOLLMAN PCH, KATAN MB, KROMHOUT D (1993) Dietary antioxidant flavonoids and risk of coronary heart disease: the Zutphen elderly study. Lancet 342: 10071011 